Marquette University

e-Publications@Marquette

\title{
Body-Focused Repetitive Behaviors and Non-Suicidal Self-Injury: A Comparison of Clinical Characteristics and Symptom Features
}

\author{
Abel S. Mathew \\ University of Wisconsin - Milwaukee \\ Taylor P. Davine \\ University of Wisconsin - Milwaukee \\ Ivar Snorrason \\ McLean Hospital \\ David C. Houghton \\ University of Texas \\ Douglas W. Woods \\ Marquette University, douglas.woods@marquette.edu
}

See next page for additional authors

Follow this and additional works at: https://epublications.marquette.edu/psych_fac

Part of the Psychology Commons

\section{Recommended Citation}

Mathew, Abel S.; Davine, Taylor P.; Snorrason, Ivar; Houghton, David C.; Woods, Douglas W.; and Lee, HanJoo, "Body-Focused Repetitive Behaviors and Non-Suicidal Self-Injury: A Comparison of Clinical Characteristics and Symptom Features" (2020). Psychology Faculty Research and Publications. 511.

https://epublications.marquette.edu/psych_fac/511 


\section{Authors}

Abel S. Mathew, Taylor P. Davine, Ivar Snorrason, David C. Houghton, Douglas W. Woods, and Han-Joo Lee 
Marquette University

e-Publications@Marquette

\title{
Psychology Faculty Research and Publications/College of Arts and Sciences
}

This paper is NOT THE PUBLISHED VERSION.

Access the published version via the link in the citation below.

Journal of Psychiatric Research, Vol. 124 (May 2020): 115-122. DOI. This article is (C) Elsevier and permission has been granted for this version to appear in e-Publications@Marquette. Elsevier does not grant permission for this article to be further copied/distributed or hosted elsewhere without express permission from Elsevier.

\section{Body-Focused Repetitive Behaviors and Non- Suicidal Self-Injury: A Comparison of Clinical Characteristics and Symptom Features}

\author{
Abel S. Mathew \\ Department of Psychology, University of Wisconsin-Milwaukee, WI \\ Taylor P. Davine \\ Department of Psychology, University of Wisconsin-Milwaukee, WI \\ Ivar Snorrason \\ Department of Psychiatry, McLean Hospital \\ David C. Houghton \\ Department of Psychiatry \& Behavioral Sciences, University of Texas Medical Branch, USA \\ Douglas W. Woods \\ Department of Psychology, Marquette University, WI \\ Han-Joo Lee \\ Department of Psychology, University of Wisconsin-Milwaukee, WI
}




\section{Highlights}

-There are debates on classification of BFRBs and non-suicidal self-injury (NSSI).

- There is a paucity of research that directly compared BFRBs and NSSI.

-We examined clinical features of BFRBs and NSSI from a large sample ( $N=1523)$.

-NSSI is performed less automatically with greater awareness than BFRBs.

-NSSI is performed more for gratifying social-affective needs than BFRBs.

\section{Abstract}

Body-focused repetitive behaviors (BFRBs) and non-suicidal self-injury (NSSI) are recognized as distinct categories in the DSM-5. However, definitions and assessment of NSSI sometimes encompasses behaviors similar to BFRBs, and little data exist about their clinical differences. The current study examined clinical characteristics and symptom features associated with NSSI vs. BFRBs. The current sample included 1523 individuals who endorsed moderate to severe NSSI $(n=165)$ or BFRBs: hair pulling group ( $n=102)$, skin picking group $(n=216)$, nail picking group $(n=253)$, nail biting group $(n=487)$, and cheek biting group $(n=300)$. Responders were asked to complete questionnaires on clinical features relevant for BFRBs and NSSI. NSSI and BFRBs had significant differences on several clinical features. Individuals in the NSSI group were more likely than individuals with BFRBs to report engaging in the behavior for social-affective reasons (i.e., to get out of doing something, or receive attention from others). Individuals in the NSSI group were also more likely to engage in the behavior to regulate tension and feelings of emptiness, and to experience relief during the act. In contrast, individuals in the BFRB groups were more likely to engage in the behavior automatically without reflective awareness, to reduce boredom, or to fix appearance. The NSSI group obtained significantly higher scores on questionnaires assessing stress, anxiety, depression, and harm avoidance. Overall, the results showed several notable differences between NSSI and BFRBs that are consistent with clinical literature and definitions of these problems in the DSM-5.

\section{Body-focused repetitive behaviors (BFRBs)}

Body-focused repetitive behaviors (BFRBs) are a group of conditions including, but not limited to, trichotillomania (TTM; hair pulling), excoriation (SPD; skin picking), nail biting, and cheek biting. Occasional engagement in mild BFRBs is common (Houghton et al., 2018) and rates of individuals with clinical levels of BFRBs are approximately 0.9-4.4\% (Grant et al., 2005; Müller et al., 2011). Moderate to severe BFRBs can result in detrimental consequences such as bald spots, sores, wounds, infections at affected areas, experiences of shame, and psychosocial impairment (Wetterneck et al., 2006).

BFRBs are often characterized by (a) feelings of tension, anxiety or boredom before committing the behavior, (b) gratification or relief while engaging in the behavior, and (c) ensuing feelings of remorse or guilt (Diefenbach et al., 2008; Wilhelm et al., 1999). Although the etiology of BFRBs is unclear, research suggests that reduced impulse control and difficulty in emotion regulation may play a role in these behaviors (Diefenbach et al., 2008; Roberts et al., 2013; Shusterman et al., 2009). Given the compulsory characteristics of BFRBs, they are classified as Obsessive-Compulsive and Related Disorders (OCRD) in the DSM-5 (APA, 2013, p. 236). 


\section{Non-suicidal self-injury (NSSI)}

Non-Suicidal Self Injury (NSSI) involves inflicting damage to one's own body without suicidal intent, such as cutting and burning oneself (Nock and Prinstein, 2004; Wilkinson et al., 2011). Currently, the behavior is listed as "conditions for further study" in the DSM-5 (APA, 2013, p. 803). A recent metaanalysis (Swannell et al., 2014) showed that the prevalence of NSSI is $17.2 \%$ among adolescents, $13.4 \%$ among young adults, and 5.5\% among adults (Swannell et al., 2014). Women are more likely to engage in NSSI and prefer certain types of behavior, such as cutting, compared to men (Bresin and Schoenleber, 2015; Favazza and Conterio, 1989; Moran et al., 2012; Nock and Prinstein, 2004).). Studies (Burke et al., 2015; Klonsky et al., 2015) show that NSSI can serve both (1) intrapersonal functions (e.g., affect regulation, anti-dissociation) and (2) social functions (e.g., interpersonal influence, peer bonding).

\section{Controversy of OCRD classification for NSSI and BFRBS}

Some researchers have adopted a broad definition of NSSI that includes skin picking, hair pulling, and other BFRBs (Favazza, 1998; McKay and Andover, 2012; Neziroglu and Mancebo, 2001; Kimbrel et al., 2014). However, these conditions are also considered to be distinct from NSSI in their clinical features, as reflected in the DSM-5. For example, SPD, TTM, and other BFRBs are not diagnosed if the behavior is better explained by NSSI. Additionally, the proposed criteria for NSSI list SPD and TTM as differential diagnoses.

\section{Clinical features of BFRBs vs. NSSI}

Research suggests that NSSI and BFRBs may have important differences in symptom presentations and clinical characteristics (Nock and Prinstein, 2004; Twohig and Woods, 2001; Wilhelm et al., 1999). First, those who engage in BFRBs often report a low level of awareness while engaging in the behavior, which may not be common in NSSI (Christenson and Mackenzie, 1994; Flessner et al., 2008a; Pacan et al., 2014; Walther et al., 2009), yet no study has compared awareness/automaticity between BFRBs and NSSI. Second, both NSSI and BFRBs occur in various emotional contexts, including boredom, intense distress, and anxiety (Teng et al., 2004; Nederkoorn et al., 2016). However, BFRBs may be more related to mundanely experienced negative emotions (e.g., daily stress, boredom, and anxiety); whereas NSSI is related to more intense and acutely distressing emotions (e.g., despair, crisis, intense feelings of emptiness). Nonetheless, research has yet to empirically determine specific and unique emotional antecedents differentiating BFRBs and NSSI.

Third, NSSI typically peaks in adolescence and declines by early adulthood (Hjelmeland and Groholt, 2005; Moran et al., 2012), while BFRBs tend to be chronic habits that persist for decades (du Toit et al., 2001; Grant and Odlaug, 2009). Neuropsychological studies have also shown that poor decision-making in adolescents with NSSI tends to improve in adulthood (Oldershaw et al., 2008). Deliberto and Nock (2008) found that individuals reported stopping their self-harm behavior for social reasons (e.g., shame, unwanted attention, upsetting family and friends), as well as understanding that it is an unhealthy and dangerous behavior. In contrast, while individuals with BFRBs reported similar social concerns, they are often unable to stop the behavior (Grant and Stein, 2014). However, the literature also suggests that addictive patterns of behavior play a significant role in NSSI (Guérin-Marion et al., 2018). Individuals who self-reported a more addictive pattern of NSSI were found to show increased frequency of the behavior, more extensive and serious self-injurious behavior, and a greater duration 
of urges. Thus, it is important to further examine the addictive/compulsive pattern of BFRBs/NSSI across time.

Taken together, existing data and clinical observations have led to discussions of clinical similarities and differences between BFRBs and NSSI; however, there is a paucity of empirical data that directly compares their similarities and differences. There is debate as to whether NSSI needs to be included in the OCRD category (see Favazza, 1998; McKay and Andover, 2012; Stanley and Cohen, 1999). Thus, a large-scale study comparing BFRBs and NSSI is important for research, diagnosis, and treatment. The current study sought to examine clinical features in BFRBs vs. NSSI in three important domains: behavioral patterns (e.g., performed automatically, in a trance, or to follow a routine), motivational factors (e.g., performed to relieve feelings of emptiness, communicate or get attention, or to avoid aversive situations), and typical consequences (e.g., reducing tension and anxiety, reducing boredom, gaining relief/gratification). We hypothesized that, relative to BFRBs, (1) behavioral patterns of NSSI would be characterized by greater awareness and deliberation, (2) individuals who engage in NSSI would be more motivated by reducing negative emotions and achieving social-affective goals (e.g., getting attention), and (3) consequences of NSSI would be characterized by greater relief and reductions of distress. Additionally, we predicted that individuals with NSSI would be characterized by greater negative affect (depression, anxiety, and stress) than individuals with BFRBs. Further, we explored whether individuals with NSSI and BFRBs would exhibit a different pattern of trait-level motivation in harm avoidance and a sense of incompleteness, which have been highlighted as important cognitive/motivational factors underlying conditions characterized by repetitive and compulsive behavioral problems like OCRDs (Ecker and Gonner, 2008; Summerfield et al., 2004; Taylor et al., 2014).

\section{Method}

\subsection{Participants}

Participants recruited for the current study were 1634 undergraduate psychology students from two mid-sized universities in the United States. Both university institutional review boards approved the study. Participants were recruited from an online research study portal. The study was open to all students enrolled in undergraduate psychology classes. A description of the study was provided on the study portal. Individuals who reported current or past BFRB/NSSI behaviors were eligible to complete the study, and they provided electronic signed informed consent.

All responders completed the following six screening questions: "In your lifetime, have you ever had the habit of excessively (1) pulling out hairs on your body (e.g., from the scalp, eyebrows, eyelashes, legs, pubic region, or anywhere else), (2) picking at your skin, (3) picking at (not biting) your nails, (4) biting your nails, (5) biting, sucking, or chewing the inside your cheeks or lips, or (6) purposely hurting yourself (e.g., by cutting or burning your skin)." The response options included: (1) Never, (2) Sometimes, but not excessively, (3) Yes, currently, and (4) Yes, but not in the past month. Participants who endorsed option 3 or 4 were presented with additional questions regarding various clinical features of the endorsed problem. Given our interest in examining clinical characteristics and other relevant factors of moderate to severe levels of BFRBs and NSSI, we included only participants who reported excessive engagement in the target behavior. Thus, participants who endorsed option 1 or 2 for all BFRB/NSSI problems were excluded from the current study. 
The final sample included 1523 individuals ( male $=30.3 \%$ and female $=69.7 \%$ ) age 18-54 years (mean age $=19.31, S D=2.54)$. Fourteen percent of the participants were Hispanic/Latino. Racial composition of the sample was as follows: Caucasian/White (72.7\%), African American/Black (3.5\%), Asian (4.0\%), Native American (0.7\%), multi-racial (4.1\%), and other (0.6\%).

\subsection{Procedures}

Following the informed consent procedure, eligible participants underwent questionnaires about demographic information (e.g., sex, age, and race/ethnicity) and various emotional variables, as well as clinical features of BFRBs and NSSI. Among the included participants, we used the following approach to identify their primary problem for the purpose of group classification. First, a severity score was calculated by summing 3-items that assessed (1) damage caused by the behavior (e.g., for hair pulling, "When the hair pulling problem was the worst (think of a 30 day period), did it cause any hair loss, or thinning?" 1 = None 5 = Extreme hair loss/thinning), (2) distress caused by the behavior (e.g., for skin picking, "When the skin picking problem was the worst, did it cause you any distress?" $1=$ No distress 5 = Extreme distress), and (3) functional impairment caused by the behavior (e.g., for selfinjury "When the self-harming problem was the worst, did it impair your functioning in any way?" 1 = No interference/impairment $\sim 5=$ Extreme interference/impairment), based on a 1-5 point scale. Thus, severity scores ranged from 3 to 15, with higher scores indicating greater severity. Then, group classification was assigned based on the behavior with the highest severity score. Participants whose highest scores were the same for more than one category were assigned to the 'tie' group. The final groups included hair pulling $(n=102$; severity score $=5.34$ [SD $=2.48]$ ), skin picking $(n=216$; severity score $=6.06$, $[S D=2.19])$, nail picking ( $n=253$; severity score $=5.63,[S D=1.97])$, nail biting ( $n=487$; severity score $=5.65,[S D=2.03])$, cheek biting $(n=300$; severity score $=5.41,[S D=1.93]$ ), and NSSI $(n=165$; severity score $=8.30,[S D=2.57])$. There were 111 individuals in the 'tie' category, and their data were excluded from the analyses for the sake of ensuring the clarity of our findings in group comparisons and minimizing the impact of co-occurring BFRBs/NSSI on their clinical features.

\subsection{Measures}

BFRBs and NSSI.

An 11-item questionnaire was developed to assess features of BFRBs and NSSI for the current study. The questionnaire assesses the extent to which an individual engages in the target behavior, and factors associated with the behavior. Three primary domains were assessed in this study: behavioral pattern, motivation, and consequences. Behavioral pattern consists of three items that evaluate the extent to which BFRBs/NSSI are completed (1) automatically without awareness, (2) while in a trancelike state, and/or (3) to follow a routine. Motivation consists of five items that assess the reasons why individuals engage in BFRBs/NSSI, including to (1) feel something (e.g., relieve feelings of emptiness), (2) communicate/get attention, (3) get away from something/someone, (4) fix appearance, and (5) achieve a "just right" feeling. Consequence consists of three items that address the perceived outcomes of BFRBs/NSSI, including (1) reduction in tension/anxiety, (2) reduction in boredom, and (3) relief/gratification. Internal consistency for the 11-items of the BFRB/NSSI questionnaire (see Table 1) was excellent $(\alpha=0.94)$.

Table 1. Eleven items of clinical features in BFRB/NSSI questionnaires.

\begin{tabular}{|l|}
\hline Behavioral Pattern \\
\hline Did the behavior occur automatically? \\
\hline
\end{tabular}




\begin{tabular}{|l|}
\hline Did the behavior occur in a trance-like state? \\
\hline Was the behavior performed as part of a routine/ritual? \\
\hline Motivation \\
\hline Was the behavior performed to feel something? \\
\hline Was the behavior performed to get attention? \\
\hline Was the behavior performed to get out of doing things? \\
\hline Was the behavior performed to fix your appearance? \\
\hline Was the behavior performed to achieve a "just right" feeling? \\
\hline Consequences \\
\hline Did the behavior reduce tension/anxiety? \\
\hline Did the behavior reduce boredom? \\
\hline Did the behavior provide relief or gratification? \\
\hline
\end{tabular}

Note. These 11 items were assessed using the following 5-point scale: $1=$ Never or Almost Never (0$10 \%) ; 2$ = A little of the time (11-35\%); 3 = Some of the time (30-70\%); 4 = Most of the time (71-89\%); $5=$ All of the time $(90-100 \%)$.

Depression, Anxiety, and Stress Scales (DASS;

Lovibond and Lovibond, 1995). The DASS-21 is a 21-item measure of emotional distress (depression, anxiety, and stress). Responses are anchored on a 4-point Likert-type scale with higher scores indicating greater emotional distress. The DASS-21 showed strong psychometric properties across subfactors, depression $(\alpha=0.94)$, anxiety $(\alpha=0.87)$, and stress $(\alpha=0.91$ ) among clinical and nonclinical samples (Antony et al., 1998). In the current sample, reliability was excellent for the total score $(\alpha=0.95)$ and depression ( $\alpha=0.92)$, and good for the anxiety $(\alpha=0.86)$ and stress $(\alpha=0.88)$ scales.

\section{Obsessive-Compulsive Trait Core Dimensions Questionnaire (OC-TCDQ;}

Summerfeldt et al., 2014). The OC-TCDQ is a 20-item measure that assesses harm avoidance (HA) and incompleteness (INC). Each item is rated from 0 (never) to 4 (always). Summerfeldt et al. (2014) reported that confirmatory factor analysis supported a two-factor structure (HA and INC). The reliability of the two factors was excellent among the clinical sample for HA $(\alpha=0.92)$ and INC $(\alpha=0.91)$, and good among the nonclinical sample for HA ( $\alpha=0.89)$ and INC $(\alpha=0.88)$. There was good convergent validity with other OC-symptom measures. The internal consistency of the OC-TCDQ in the current sample was excellent for HA $(\alpha=0.93)$ and INC $(\alpha=0.93)$.

\section{Results}

To test clinical similarities and differences between BFRBs and NSSI, a series of one-way ANOVAs were conducted to examine group differences between BFRBs and NSSI on each of the clinical characteristics of interest. Bonferroni correction was used to control for Type I error inflation in multiple comparisons $(.05 / 11)$ with statistical significance at $p=.004$. Following up on a significant F-test result, we conducted Bonferroni post-hoc comparisons to identify the location of group differences.

\subsection{Clinical characteristics}

A chi-square test for gender by condition was statistically significant $\left(\chi^{2}=32.11, p<.001\right)$ (Table 2$)$. Overall, the percentage of females appeared to be higher in the NSSI group ( $=84.9 \%$ females, $15.1 \%$ males) than the average of the entire sample ( $=69.7 \%$ females, $30.3 \%$ males). On average, the BFRB categories together included $68.5 \%$ of females and $31.5 \%$ of males. This pattern of gender distribution is largely consistent with the literature (Bresin and Schoenleber, 2015; Favazza and Conterio, 1989; 
Moran et al., 2012; Nock and Prinstein, 2004, APA, 2013). Participants were placed in specific categories based on the primary problem endorsed. Table 3 shows the total number of individuals who reported BFRB/NSSI problems. The results reveal that $62 \%(n=947)$ of the individuals reported a single BFRB/NSSI (as the primary problem) with no other co-occurring BFRB/NSSI, 26\% $(n=398)$ had 1 additional BFRB/NSSI, 9\% $(n=140)$ reported 2 additional BFRBs/NSSI, $2 \%(n=35)$ endorsed 3 additional BFRBs/NSSI, $1 \%(n=13)$ had 4 additional BFRBs/NSSI, and less than $1 \%(n=2)$ reported 5 BFRBs/NSSI. 
Table 2. Means and SDs of phenomenological measures of BFRBS and NSSI.

\begin{tabular}{|c|c|c|c|c|c|c|c|c|c|c|c|c|}
\hline & HP & & SP & & NP & & NB & & CB & & NSSI & \\
\hline & Mean & SD & Mean & SD & Mean & SD & Mean & SD & Mean & SD & Mean & SD \\
\hline \multicolumn{13}{|l|}{ BFRB/NSSI Questionnaire } \\
\hline Performed automatically & 3.31 & 1.36 & 3.25 & 1.21 & 3.49 & 1.18 & 3.70 & 1.07 & 3.75 & 1.15 & 1.66 & 1.03 \\
\hline Performed while in a trance & 2.71 & 1.32 & 2.41 & 1.25 & 2.43 & 1.20 & 2.49 & 1.25 & 2.47 & 1.29 & 2.38 & 1.39 \\
\hline Performed as a routine/ritual & 1.54 & 1.02 & 1.50 & 0.96 & 1.28 & 0.69 & 1.21 & 0.63 & 1.25 & 0.72 & 1.82 & 1.29 \\
\hline Performed to feel something & 1.81 & 1.18 & 1.45 & 0.86 & 1.38 & 0.80 & 1.36 & 0.83 & 1.50 & 1.01 & 3.93 & 1.10 \\
\hline Performed to get attention & 1.32 & 0.83 & 1.10 & 0.43 & 1.20 & 0.63 & 1.11 & 0.42 & 1.16 & 0.58 & 1.95 & 1.23 \\
\hline Performed to 'get away' & 1.39 & 0.86 & 1.20 & 0.64 & 1.22 & 0.63 & 1.16 & 0.55 & 1.15 & 0.60 & 1.44 & 0.95 \\
\hline Performed to fix appearance & 2.31 & 1.48 & 2.56 & 1.50 & 1.70 & 1.09 & 1.44 & 0.83 & 1.29 & 0.75 & 1.35 & 0.91 \\
\hline Performed for 'just right' feeling & 1.95 & 1.18 & 1.79 & 1.22 & 1.61 & 1.04 & 1.61 & 1.05 & 1.58 & 0.98 & 2.55 & 1.51 \\
\hline Reduced tension & 2.38 & 1.14 & 2.18 & 1.20 & 2.33 & 1.15 & 2.53 & 1.19 & 2.58 & 1.22 & 3.70 & 1.17 \\
\hline Reduced boredom & 2.96 & 1.28 & 2.84 & 1.30 & 2.87 & 1.15 & 2.95 & 1.16 & 2.68 & 1.22 & 1.79 & 1.17 \\
\hline Provided gratification/relief & 2.57 & 1.33 & 2.42 & 1.24 & 2.15 & 1.13 & 2.18 & 1.19 & 2.25 & 1.26 & 3.70 & 1.15 \\
\hline \multicolumn{13}{|l|}{ OCTCDQ } \\
\hline Harm Avoidance & 20.97 & 8.11 & 23.14 & 9.16 & 21.48 & 8.99 & 21.94 & 9.07 & 22.59 & 9.22 & 26.09 & 9.92 \\
\hline Incompleteness & 24.64 & 9.25 & 25.80 & 9.59 & 23.78 & 9.39 & 24.28 & 9.53 & 24.77 & 9.85 & 27.22 & 9.89 \\
\hline \multicolumn{13}{|l|}{ DASS } \\
\hline Stress & 26.88 & 9.55 & 27.06 & 9.02 & 25.11 & 9.16 & 24.89 & 9.04 & 26.91 & 9.64 & 33.37 & 11.03 \\
\hline Anxiety & 22.14 & 9.25 & 21.38 & 8.01 & 20.68 & 7.94 & 20.08 & 7.18 & 21.50 & 8.18 & 27.35 & 11.16 \\
\hline Depression & 23.80 & 9.96 & 22.99 & 8.10 & 22.58 & 8.91 & 21.73 & 8.64 & 23.73 & 10.30 & 31.88 & 12.73 \\
\hline Total & 72.82 & 26.31 & 71.42 & 23.84 & 68.37 & 23.85 & 66.70 & 22.40 & 72.06 & 25.61 & 92.60 & 31.74 \\
\hline \multicolumn{13}{|l|}{ Age and Duration } \\
\hline Age of Onset & 13.57 & 4.23 & 12.77 & 4.29 & 11.14 & 4.44 & 9.76 & 3.61 & 13.11 & 4.21 & 14.36 & 2.76 \\
\hline Duration of Symptoms & 3.27 & 3.40 & 5.82 & 4.52 & 6.73 & 4.12 & 7.65 & 4.40 & 5.24 & 3.97 & 3.40 & 2.87 \\
\hline \% Symptom Free & $45 \%$ & & $30 \%$ & & $37 \%$ & & $44 \%$ & & $29 \%$ & & $78 \%$ & \\
\hline \% Male & $32 \%$ & & $26 \%$ & & $37 \%$ & & $35 \%$ & & $28 \%$ & & $31 \%$ & \\
\hline$\%$ Female & $68 \%$ & & $74 \%$ & & $63 \%$ & & $65 \%$ & & $72 \%$ & & $69 \%$ & \\
\hline
\end{tabular}

Note. $\mathrm{HP}=$ hair pulling, $\mathrm{SP}=$ skin picking, $\mathrm{NP}=$ nail picking, $\mathrm{NB}=$ nail biting, $\mathrm{CB}=$ cheek biting, $\mathrm{NSSI}=$ non-suicidal self-injury.

Table 3. The number of co-occurring BFRBs/NSSI per group. 


\begin{tabular}{|c|c|c|c|c|c|c|c|c|c|c|c|c|c|}
\hline $\begin{array}{l}\text { Primary } \\
\text { Category }\end{array}$ & $\begin{array}{l}\text { No } \\
\text { additional }\end{array}$ & & $\begin{array}{l}1 \\
\text { additional }\end{array}$ & & \begin{tabular}{|l} 
\\
additional \\
\end{tabular} & & $\begin{array}{l}\mathbf{3} \\
\text { additional }\end{array}$ & & \begin{tabular}{|l}
4 \\
additional \\
\end{tabular} & & $\begin{array}{l}\mathbf{5} \\
\text { additional }\end{array}$ & & Total \\
\hline & $\mathrm{n}$ & $\%$ & $\mathrm{n}$ & $\%$ & $n$ & $\%$ & $\mathrm{n}$ & $\%$ & $n$ & $\%$ & $n$ & $\%$ & $n$ \\
\hline $\mathrm{HP}$ & 70 & 67.31 & 24 & 23.08 & 9 & 8.65 & 1 & 0.96 & 0 & 0.00 & 0 & 0.00 & 104 \\
\hline SP & 136 & 62.39 & 50 & 22.94 & 22 & 10.09 & 7 & 3.21 & 2 & 0.92 & 1 & 0.45 & 218 \\
\hline NP & 168 & 66.40 & 64 & 25.30 & 16 & 6.32 & 3 & 1.19 & 2 & 0.79 & 0 & 0.00 & 253 \\
\hline NB & 315 & 64.29 & 130 & 26.53 & 36 & 7.35 & 6 & 1.22 & 2 & 0.41 & 1 & 0.20 & 490 \\
\hline $\mathrm{CB}$ & 195 & 65.00 & 70 & 23.33 & 26 & 8.67 & 7 & 2.33 & 2 & 0.67 & 0 & 0.00 & 300 \\
\hline NSSI & 63 & 37.95 & 60 & 36.14 & 29 & 17.47 & 9 & 5.42 & 5 & 3.01 & 0 & 0.00 & 166 \\
\hline Total & 947 & 61.69 & 398 & 25.92 & 140 & 9.10 & 35 & 2.28 & 13 & 0.84 & 2 & 0.13 & 1535 \\
\hline
\end{tabular}

Note. No additional $=$ Having the primary problem with no other co-occurring BFRB/NSSI; 1 additional = Having the primary problem with one additional BFRB/NSSI $\sim 5$ additional = Having the primary problem with five additional BFRBs/NSSI. 
Behavioral pattern: Performed automatically without awareness.

There was a significant group difference in behavioral automaticity, $F(5,1517)=90.22, p<.001$. The NSSI group (mean $=1.66, S D=1.03$ ) reported less automaticity than individuals in the hair pulling group (mean $=3.31, S D=1.36$ ), skin picking group (mean $=3.25, S D=1.21$ ), nail picking group ( mean $=3.49, S D=1.18)$, nail biting group (mean $=3.70, S D=1.07)$, and cheek biting group $($ mean $=3.75, S D=1.15)$, $p s<.001$.

Behavioral pattern: Performed while in a trance.

A one-way ANOVA revealed no significant differences between groups, $F(5,1517)=1.03, p=.40$.

Behavioral pattern: Performed to follow routine before or after behavior.

There was a significant group difference, $F(5,1517)=16.80, p<.001$. With the exception of the hair pulling group $(p=.11$ ), the NSSI group (mean $=1.82, S D=1.29$ ) reported greater routine behaviors than all other BFRB groups, skin picking group (mean $=1.50, S D=0.96$ ), nail picking group ( mean $=1.28, S D=0.69)$, nail biting group (mean $=1.21, S D=0.63)$, and cheek biting group $($ mean $=1.25, S D=0.72)$, ps $<.004$.

Motivation: Performed to feel something (i.e, relieve feelings of emptiness).

There was a significant group difference, $F(5,1517)=216.53, p<.001$. The NSSI group (mean $=3.93$, $S D=1.10$ ) reported engaging in NSSI more to relieve feelings of emptiness, relative to the hair pulling group (mean $=1.18, S D=1.18)$, skin picking group (mean $=1.45, S D=0.86)$, nail picking group $($ mean $=1.38, S D=0.80)$, nail biting group $($ mean $=1.36, S D=0.83)$, and cheek biting group $($ mean $=0.50, S D=1.01)$, ps $<.001$.

Motivation: Performed to communicate or to get attention. There was a significant group difference, $F(5,1517)=46.32, p<.001$. The NSSI group ( mean $=1.95$, $S D=1.23$ ) reported a greater motivation to communicate or seek attention than the hair pulling group ( mean $=1.32, S D=0.83)$, skin picking group $($ mean $=1.10, S D=0.43)$, nail picking group ( mean $=1.20$, $S D=0.63)$, nail biting group (mean $=1.11, S D=0.42)$, and cheek biting group (mean $=1.16, S D=0.58)$, ps $<.001$.

Motivation: Performed to get away from something or someone.

There was a significant group difference, $F(5,1517)=6.65, p<.001$. The NSSI group (mean $=1.44$, $S D=0.95$ ) reported a greater intention for "getting away from something/someone" than the nail biting group (mean $=1.16, S D=0.55)$ and cheek biting group (mean $=1.15, S D=0.60), p s<.001$, but not the hair pulling group (mean $=1.39, S D=0.86$ ), skin picking group ( $m e a n=1.20, S D=0.64$ ), and nail picking group $($ mean $=1.22, S D=0.63)$, $p s>.004$.

Motivation: Performed to fix aspect of appearance.

There was a significant group difference, $F(5,1517)=55.13, p<.001$. The NSSI group ( mean $=1.35$, $S D=0.91$ ) reported less intention for altering appearance, relative to the hair pulling group ( mean $=2.31, S D=1.48$ ) and skin picking group ( mean $=2.56, S D=1.50)$, $p s<.001$, but not the nail picking group (mean $=1.70, S D=1.09)$, nail biting group ( $m e a n=1.44, S D=0.83$ ), and cheek biting group $($ mean $=1.29, S D=0.75)$, $p s>.004$. 
Motivation: When performing, trying to achieve a "just right" feeling.

There was a significant group difference, $F(5,1517)=90.22, p<.001$. The NSSI group ( mean $=2.55$, $S D=1.51$ ) had greater intentions to gain a "just right" feeling relative to the hair pulling group

( mean $=1.95, S D=1.18)$, skin picking group (mean $=1.79, S D=1.22)$, nail picking group (mean $=1.16$, $S D=1.04)$, nail biting group (mean $=1.61, S D=1.05)$, and cheek biting group (mean $=1.58, S D=0.98)$, ps $<.004)$.

Consequence: Reduction in tension and anxiety.

There was a significant group difference, $F(5,1517)=37.38, p<.001$. The NSSI group ( mean $=3.70$, $S D=1.17)$ reported more engagement in NSSI to reduce tension and anxiety than the hair pulling group ( mean $=2.38, S D=1.14$ ), skin picking group (mean $=2.18, S D=1.20)$, nail picking group ( mean - = 2.33, $S D=1.19$ ), nail biting group (mean $=2.53, S D=1.19)$, and cheek biting group ( mean $=2.58$, $S D=1.22)$, ps $<.001$.

Consequence: Reduction in boredom.

There was a significant group difference, $F(5,1517)=25.23, p<.001$. The NSSI group ( mean $=1.79$, $S D=1.17$ ) reported less reduction in boredom than the hair pulling group ( mean $=2.96, S D=1.28$ ), skin picking group (mean $=2.84, S D=1.30)$, nail picking group (mean $=2.87, S D=1.15)$, nail biting group (mean $=2.95, S D=1.16)$, and cheek biting group $($ mean $=2.68, S D=1.22)$, $p s<.001$.

Consequence: Relief or gratification.

There was a significant group difference, $F(5,1517)=44.70, p<.001$. The NSSI group ( mean $=3.70$, $S D=1.15$ ) reported greater experience of relief or gratification than the hair pulling group (mean $=2.57, S D=1.33)$, skin picking group (mean $=2.42, S D=1.24)$, nail picking group ( mean $=2.15$, $S D=1.13)$, nail biting group (mean $=2.18, S D=1.19)$, and cheek biting group (mean $=2.25, S D=1.26)$, ps $<.001$. $^{2}$

Age of onset.

There was a significant group difference in age of onset, $F(5,1494)=54.17, p<.001$ (Table 2). The NSSI group reported that symptoms emerged at older age (mean age $=14.36, \mathrm{SD}=2.76$ ) than the skin picking (mean age $=12.77, S D=4.29$ ), nail picking (mean age $=11.14, S D=4.44$ ), and nail biting (mean age $=9.76, S D=3.61$ ) groups, $p s<.004$. There was no significant difference between the NSSI group and the hair pulling (mean age $=13.57, S D=4.23$ ) and cheek biting groups (mean age $=13.11$, $S D=2.53)$, ps $>.004$.

Emotional distress: Depression, anxiety, and stress.

There were significant differences between groups across DASS-Depression $F(5,1504)=28.11$, $p<.001$, DASS-Anxiety $F(5,1504)=19.76, p<.001$, and DASS-Stress, $F(5,1504)=21.33, p<.001$. The NSSI group reported significantly higher levels of depression (mean $=31.88, S D=12.73$ ) than the BFRB groups (means range $=21.73$ to 23.8 , SDs range $=8.64$ to 9.96), $p s<.001$, higher levels of anxiety ( mean $=27.35, S D=11.16$ ) than the BFRB groups (means range $=20.08$ to 22.14 , SDs range $=7.18$ to 9.25 ), and higher levels of stress (mean $=33.37, S D=11.03$ ) than the BFRB groups (means range $=24.86$ to 27.06 , SDs range $=9.02$ to 9.64 ) . 
Obsessive-Compulsive Trait Dimensions.

There were significant group differences in Harm Avoidance, $F(5,1503)=6.77, p<.001$. The NSSI group reported significantly higher scores (mean $=26.09, S D=9.92$ ) of harm avoidance than the BFRB groups (means ranged $=20.97$ to $23.14, S D s=8.11$ to 9.22 ), $p s<.05$. There was no significant difference in harm avoidance scores among the various BFRBs. There were also significant group differences in incompleteness scores, $F(5,1502)=3.36, p=.005)$. Bonferroni post-hoc analysis showed that the NSSI group was significantly higher than nail picking ( mean $=23.78, S D=9.39$ ) and nail biting ( $m e a n=24.28$, $S D=9.53$ ), but not hair pulling, skin picking, and cheek biting groups. Table 4 provides a summarized result of the similarities and differences between NSSI and BFRBs.

Table 4. Summary of results for one-way ANOVAs comparing BFRBs and NSSI.

\begin{tabular}{|c|c|c|c|}
\hline Clinical Features & BFRBs & NSSI & Notes \\
\hline Reduced tension & Lower & Higher & \\
\hline Reduced boredom & Higher & Lower & \\
\hline Produced gratification/relief & Lower & Higher & \\
\hline Performed automatically & Higher & Lower & \\
\hline Performed while in a trance & $\begin{array}{l}\text { No } \\
\text { difference }\end{array}$ & $\begin{array}{l}\text { No } \\
\text { difference }\end{array}$ & \\
\hline $\begin{array}{l}\text { Performed to feel } \\
\text { something }\end{array}$ & Lower & Higher & \\
\hline Performed to get attention & Lower & Higher & \\
\hline Performed to 'get away' & Lower & Higher & No differences between NSSI and HP \\
\hline Performed to fix appearance & Higher & Lower & $\begin{array}{l}\text { No differences between NSSI and NB, } \\
N P \text {, and CB }\end{array}$ \\
\hline $\begin{array}{l}\text { Performed as a } \\
\text { routine/ritual }\end{array}$ & Lower & Higher & No differences between NSSI and HP \\
\hline $\begin{array}{l}\text { Performed for 'just right' } \\
\text { feeling }\end{array}$ & Lower & Higher & \\
\hline Stress & Lower & Higher & \\
\hline Anxiety & Lower & Higher & \\
\hline Depression & Lower & Higher & \\
\hline Harm Avoidance & Lower & Higher & NSSI greater than NP and NB \\
\hline Incompleteness & Mixed & Mixed & $\begin{array}{l}\text { No differences between NSSI and HP, } \\
\text { SP, CB }\end{array}$ \\
\hline
\end{tabular}

Note: $\mathrm{HP}=$ hair pulling; $\mathrm{SP}=$ skin picking; $\mathrm{NB}=$ nail biting; $\mathrm{NP}=$ nail picking; $\mathrm{CB}=$ cheek biting; NSSI = non-suicidal self-injury.

\section{Discussion}

Given uncertainty about the classification of BFRBs and NSSI (Klonsky, 2011; McKay and Andover, 2012; Nock and Favazza, 2009; Sacks et al., 2008), this study sought to acquire empirical data to compare clinical features between BFRBs and NSSI to better understand their similarities and differences. Our data demonstrated that BFRBs and NSSI can be distinguished across important clinical features. In terms of the overall behavioral pattern, BFRBs were more likely than NSSI to be performed with reduced awareness. Thus, automaticity does not appear to be a prominent feature of NSSI compared 
to various BFRBs. Relative to BFRBs, NSSI was also more strongly associated with specific socialaffective goals aimed at gratifying one's emotional needs (e.g., to feel something/reduce feelings of emptiness, to communicate/receive attention, to avoid unwanted circumstances, and/or to gain a "just right" feeling). Similarly, other studies showed that individuals with NSSI report engaging in self-harm to reduce negative affect, signal personal distress to others, express anger, punish oneself, generate normal feelings, and distract oneself (Brown et al., 2002; Lloyd-Richardson et al., 2007; Wilkinson and Goodyer, 2011). In contrast, those with BFRBs endorsed wanting "to fix aspects of appearance" more than those with NSSI, which may reflect their urges to perform body-focused behaviors (e.g., the need to smooth out skin imperfections, pull out hair that appears out of place, or bite irregularities on nails or skin). Thus, NSSI is more likely to be related to affective reasons, whereas BFRBs are more likely to be linked to appearance-related reasons.

Additionally, regarding emotional consequences and correlates, NSSI is characterized by the reduction in tension or anxiety, and experiences of relief and gratification. Conversely, BFRBs are characterized more by a reduction in boredom. Relatedly, our data showed that NSSI is associated with higher levels of depression, stress, and anxiety than BFRBs. Existing findings also support that BFRBs occur for a variety of reasons including boredom, as well as anxiety/tension (Penzel, 2003; Snorrason et al., 2010). Thus, overall findings indicate that one's negative affective state (i.e., depression and anxiety) is greatly pronounced in NSSI, and reducing such negative emotions is a more important consequence intended by NSSI, relative to BFRBs. Additionally, we found that those with NSSI reported a higher level of harm avoidance than those with BFRBs. Harm avoidance is a personality trait strongly associated with the experience of negative affect, especially depressive symptoms (Abrams et al., 2004; Brown et al., 1992; Cloninger et al., 2006; Elovainio et al., 2004; Hansenne et al., 1999). In sum, these data suggest the possibility that NSSI is more strongly related to down-regulation of negative affect, relative to BFRBs.

Taken together, the current data indicate that NSSI is clearly distinguished from BFRBs in several aspects. Relative to BFRBs, NSSI is less automatic, and oriented toward emotional goals (e.g., reducing negative feelings) and social-affective goals (e.g., getting attention/avoiding someone).

This distinctive pattern of clinical features yields important implications for clinical intervention. For example, since NSSI rarely occurs without awareness, habit reversal training (HRT), a therapeutic technique that focuses on awareness training (Azrin et al., 1980) may not be appropriate for this problem, whereas awareness training evaluating the antecedents, emotions, and consequences of the behavior would be crucial in addressing BFRBs. In contrast, focusing directly on emotional dysregulation and maladaptive motivations of the behavior (e.g., Dialectical Behavior Therapy) may be a more important treatment approach for NSSI (Hawton et al., 1998; Muehlenkamp, 2005; Suyemoto, 1998). NSSI is employed heavily in the presence of negative affect to cope with both internalizing and externalizing disorders (Peterson et al., 2008).

There are several limitations that should be noted. First, the current study relied on self-report measures for classification of BFRB/NSSI problems. Although we assessed multiple domains of target symptoms (i.e., damage, distress, and impairment) to identify one's primary BFRB/NSSI problem, the exclusive reliance on self-report measures for classification is clearly a limitation of the study. Future research may employ clinical interview-based measures to assess individuals with BFRBs/NSSI. Second, the current data were obtained from a large student sample, although we included only individuals who clearly endorsed the experience of BFRBs/NSSI through a prescreening procedure. Replication is 
required to further evaluate the pattern of findings, using a clinical sample that display moderate to severe levels of BFRB/NSSI symptoms with marked distress and impairment in functioning. Third, in order to compare their clinical features across well-recognized BFRB/NSSI categories, we classified individuals into discrete BFRB/NSSI groups based on their primary condition. Nevertheless, this may not be the most ideal analytic approach given many individuals reported co-occurring BFRBs/NSSI across multiple categories and a single primary category may not adequately represent clinical manifestations. Future research may include an advanced analytic technique (e.g., latent class model) to identify the subgroups of BFRB/NSSI, which more accurately reflect the underlying pattern of complex multivariate data among the affected individuals. Fourth, we treated NSSI as a single category, although there may be heterogeneous subgroups of NSSI with different functions or clinical features

(e.g., deliberate vs non-deliberate self-harm, Jacobson et al., 2008; positively-reinforcing vs. negativelyreinforcing NSSI, Zetterqvist et al., 2013). It is important to assess different types of NSSI as they can show different clinical features, including endorsement rates (Robinson and Wilson, 2019). Future investigations should systematically examine potentially diverse clinical features within various patterns of NSSI. Fifth, in order to include a variety of individuals with NSSI and BFRBs, inclusion criteria were based on a limited scope of these problems (i.e., the frequency of engagement within one's lifetime), not taking into account severity or impairment. However, it should be noted that our screening question was asking them to indicate the frequency of "excessive" engagement of NSSI or BFRBs. Further, we subsequently considered severity and impairment caused by these problems, which enabled us to identify the primary problems distributed across all BFRB/NSSI categories. Future studies need to consider developing a more comprehensive approach to screen and identify individuals presenting with clinical levels of NSSI/BFRB problems. Sixth, severity scores, which were used to identify one's primary behavior, revealed that the NSSI group showed an overall greater level of severity, relative to the BFRB groups. It is beyond the scope of the current study to systematically assess and compare overall clinical severity across various BFRB/NSSI conditions. Evidence suggests that clinical severity could significantly vary even within the NSSI group as a function of the type of behaviors (e.g., picking vs. cutting; Croyle and Waltz, 2007). It is important for future research to examine the overall clinical severity of various BFRB/NSSI problems more adequately, while systematically addressing the clinical heterogeneity within these conditions. Finally, we did not directly assess appearance concerns related to body dysmorphic disorder (BDD) in this study, so we are not able to tell if elevated appearance concerns in BFRBs (such as skin picking) were indeed reflective of the symptoms of BDD. Studies have shown that individuals with BDD often pick skin in order to correct perceived flaws in appearance (Grant et al., 2006). However, the prevalence of BDD appears to be relatively low among those with skin picking problems (Grant et al., 2010), which suggests that BDDrelated skin picking may represent a relatively distinct clinical phenomenon compared to skin picking in SPD (Snorrason et al., 2013). Nevertheless, we cannot rule out the possibility that the elevated appearance concerns in BFRBs within the current study was to some degree accounted for by BDDrelated concerns. Future research should systematically assess BDD-related concerns and its comorbidity, to better understand the distinctive features of BFRBs that involve concerns about appearance (APA, 2013). Despite the limitations, the current data are expected to contribute to the literature by demonstrating important differences in clinical features between BFRB and NSSI conditions. Improved knowledge of their distinctive clinical features will likely help the field accurately identify, assess, and treat individuals displaying these problems.

\section{Declaration of competing interest}

The authors of the current manuscript have no conflict of interest to report. 


\section{CRediT authorship contribution statement}

Abel S. Mathew: Conceptualization, Writing - original draft. Taylor P. Davine: Conceptualization, Writing - original draft. Ivar Snorrason: Conceptualization, Writing - original draft, Data curation, Writing - review \& editing. David C. Houghton: Writing - original draft, Writing - review \& editing. Douglas W. Woods: Conceptualization, Writing - review \& editing. Han-Joo Lee: Conceptualization, Writing - original draft.

\section{References}

Abrams et al., 2004. K.Y. Abrams, S.K. Yune, S.J. Kim, H.J. Jeon, S.J. Han, J. Hwang, ..., I.K. Lyoo. Trait and state aspects of harm avoidance and its implication for treatment in major depressive disorder, dysthymic disorder, and depressive personality disorder. Psychiatr. Clin. Neurosci., 58 (3) (2004), pp. 240-248

American Psychiatric Association, 2013. American Psychiatric Association. Diagnostic and Statistical Manual of Mental Disorders (DSM-5 ${ }^{\circledR}$ ). American Psychiatric Pub (2013).

Antony et al., 1998. M.M. Antony, P.J. Bieling, B.J. Cox, M.W. Enns, R.P. Swinson. Psychometric properties of the 42-item and 21-item versions of the Depression Anxiety Stress Scales in clinical group and a community sample. Psychol. Assess., 10 (2) (1998), pp. 176-181

Azrin et al., 1980. N.H. Azrin, R.G. Nunn, S.E. Frantz. Treatment of hairpulling (trichotillomania): a comparative study of habit reversal and negative practice training. J. Behav. Ther. Exp. Psychiatr., 11 (1) (1980), pp. 13-20

Bresin and Schoenleber, 2015. K. Bresin, M. Schoenleber. Gender differences in the prevalence of nonsuicidal self-injury: a meta-analysis. Clin. Psychol. Rev., 38 (2015), pp. 55-64

Brown et al., 2002. M.Z. Brown, K.A. Comtois, M.M. Linehan. Reasons for suicide attempts and nonsuicidal self-injury in women with borderline personality disorder. J. Abnorm. Psychol., 111 (1) (2002), pp. 198-202

Brown et al., 1992. S.L. Brown, D.M. Svrakic, T.R. Przybeck, R.C. Cloninger. The relationship of personality to mood and anxiety states: a dimensional approach. J. Psychiatr. Res., 26 (3) (1992), pp. 197-211

Burke et al., 2015. T.A. Burke, J.L. Hamilton, L.Y. Abramson, L.B. Alloy. Non-suicidal self-injury prospectively predicts interpersonal stressful life events and depressive symptoms among adolescent girls. Psychiatr. Res., 228 (3) (2015), pp. 416-424

Christenson and Mackenzie, 1994. G.A.H. Christenson, T.B. Mackenzie. Trichotillomania. Handbook of Prescriptive Treatments for Adults, Springer, Boston, MA (1994), pp. 217-235

Cloninger et al., 2006. C.R. Cloninger, D.M. Svrakic, T.R. Przybeck. Can personality assessment predict future depression? A twelve-month follow-up of 631 subjects. J. Affect. Disord., 92 (1) (2006), pp. 35-44

Croyle and Waltz, 2007. K.L. Croyle, J. Waltz. Subclinical self-harm. Range of behaviors, extent, and associated characteristics. Am. J. Orthopsychiatry, 77 (2) (2007), pp. 332-342

Deliberto and Nock, 2008. T.L. Deliberto, M.K. Nock. An exploratory study of correlates, onset, and offset of non-suicidal self-injury. Arch. Suicide Res., 12 (3) (2008), pp. 219-231

Diefenbach et al., 2008. G.J. Diefenbach, D.F. Tolin, S. Meunier, P. Worhunsky. Emotion regulation and trichotillomania: a comparison of clinical and nonclinical hair pulling. J. Behav. Ther. Exp. Psychiatr., 39 (1) (2008), pp. 32-41 
du Toit et al., 2001. P.L. du Toit, J. van Kradenburg, D.J. Niehaus, D.J. Stein. Characteristics and phenomenology of hair-pulling: an exploration of subtypes. Compr. Psychiatr., 42 (2001), pp. 247-256

Ecker and Gönner, 2008. W. Ecker, S. Gönner. Incompleteness and harm avoidance in OCD symptom dimensions. Behav. Res. Ther., 46 (8) (2008), pp. 895-904

Elovainio et al., 2004. M. Elovainio, M. Kivimäki, S. Puttonen, T. Heponiemi, L. Pulkki, L. KeltikangasJärvinen. Temperament and depressive symptoms: a population-based longitudinal study on Cloninger's psychobiological temperament model. J. Affect. Disord., 83 (2-3) (2004), pp. 227232

Favazza, 1998. A.R. Favazza. The coming of age of self-mutilation. J. Nerv. Ment. Dis., 186 (5) (1998), pp. 259-268

Favazza and Conterio, 1989. A.R. Favazza, K. Conterio. Female habitual self-mutilators. Acta Psychiatr. Scand., 79 (3) (1989), pp. 283-289

Flessner et al., 2008a. C.A. Flessner, C.A. Conelea, D.W. Woods, M.E. Franklin, N.J. Keuthen, S.E. Cashin. Styles of pulling in trichotillomania: exploring differences in symptom severity, phenomenology, and functional impact. Behav. Res. Ther., 46 (3) (2008), pp. 345-357

Grant et al., 2005. J.E. Grant, L. Levine, D. Kim, M.N. Potenza. Impulse control disorders in adult psychiatric inpatients. Am. J. Psychiatr., 162 (11) (2005), pp. 2184-2188

Grant et al., 2006. J.E. Grant, W. Menard, K.A. Phillips. Pathological skin picking in individuals with body dysmorphic disorder. Gen. Hosp. Psychiatr., 28 (2006), pp. 487-493

Grant and Odlaug, 2009. J.E. Grant, B.L. Odlaug. Obsessive-compulsive spectrum and disorders of the skin. Expet Rev. Dermatol., 4 (5) (2009), pp. 523-532

Grant et al., 2010. J.E. Grant, B.L. Odlaug, S.W. Kim. A clinical comparison of pathologic skin picking and obsessive-compulsive disorder. Compr. Psychiatr., 51 (2010), pp. 347-352

Grant and Stein, 2014. J.E. Grant, D.J. Stein. Body-focused repetitive behavior disorders in ICD-11. Rev. Bras. Psiquiatr., 36 (1) (2014), pp. 59-64

Guérin-Marion et al., 2018. C. Guérin-Marion, J. Martin, A.A. Deneault, M.F. Lafontaine, J.F. Bureau. The functions and addictive features of non-suicidal self-injury: a confirmatory factor analysis of the Ottawa self-injury inventory in a university sample. Psychiatr. Res., 264 (2018), pp. 316321

Hansenne et al., 1999. M. Hansenne, J. Reggers, E. Pinto, K. Kjiri, A. Ajamier, M. Ansseau. Temperament and character inventory (TCI) and depression. J. Psychiatr. Res., 33 (1) (1999), pp. 31-36

Hawton et al., 1998. K. Hawton, E. Arensman, E. Townsend, S. Bremner, E. Feldman, R. Goldney, ..., D. Owens. Deliberate self harm: systematic review of efficacy of psychosocial and pharmacological treatments in preventing repetition. BMJ, 317 (7156) (1998), pp. 441-447

Hjelmeland and Grøholt, 2005. H. Hjelmeland, B. Grøholt. A comparative study of young and adult deliberate self-harm patients. Crisis, 26 (2) (2005), pp. 64-72

Houghton et al., 2018. D.C. Houghton, J.R. Alexander, C.C. Bauer, D.W. Woods. Abnormal perceptual sensitivity in body-focused repetitive behaviors. Compr. Psychiatr., 82 (2018), pp. 45-52

Jacobson et al., 2008. C.M. Jacobson, J.J. Muehlenkamp, A.L. Miller, J.B. Turner. Psychiatric impairment among adolescents engaging in different types of deliberate self-harm. J. Clin. Child Adolesc. Psychol., 37 (2008), pp. 363-375

Kimbrel et al., 2014. N.A. Kimbrel, M.E. Johnson, C. Clancy, M. Hertzberg, C. Collie, E.E. Van Voorhees, et al. Deliberate self-harm and suicidal ideation among male Iraq/Afghanistan-era veterans seeking treatment for PTSD. J. Trauma Stress, 27 (4) (2014), pp. 474-477 
Klonsky, 2011. E.D. Klonsky. Non-suicidal self-injury in United States adults: prevalence, sociodemographics, topography and functions. Psychol. Med., 41 (9) (2011), pp. 1981-1986

Klonsky et al., 2015. E.D. Klonsky, C.R. Glenn, D.M. Styer, T.M. Olino, J.J. Washburn. The functions of nonsuicidal self-injury: converging evidence for a two-factor structure. Child Adolesc. Psychiatr. Ment. Health, 9 (1) (2015), p. 44

Lloyd-Richardson et al., 2007. E.E. Lloyd-Richardson, N. Perrine, L. Dierker, M.L. Kelley. Characteristics and functions of non-suicidal self-injury in a community sample of adolescents. Psychol. Med., 37 (8) (2007), pp. 1183-1192

Lovibond and Lovibond, 1995. S.H. Lovibond, P.F. Lovibond. The structure of negative emotional states: comparison of the depression anxiety stress scales (DASS) with the beck depression and anxiety inventories. Behav. Res. Ther., 33 (3) (1995), pp. 335-343

McKay and Andover, 2012. D. McKay, M. Andover. Should nonsuicidal self-injury be a putative obsessive-compulsive-related condition? A critical appraisal. Behav. Modif., 36 (1) (2012), pp. 3-17

Moran et al., 2012. P. Moran, C. Coffey, H. Romaniuk, C. Olsson, R. Borschmann, J.B. Carlin, G.C. Patton. The natural history of self-harm from adolescence to young adulthood: a populationbased cohort study. Lancet, 379 (9812) (2012), pp. 236-243

Muehlenkamp, 2005. J.J. Muehlenkamp. Self-injurious behavior as a separate clinical syndrome. Am. J. Orthopsychiatry, 75 (2) (2005), pp. 324-333

Müller et al., 2011. A. Müller, K. Rein, I. Kollei, A. Jacobi, A. Rotter, P. Schütz, ..., M. de Zwaan. Impulse control disorders in psychiatric inpatients. Psychiatr. Res., 188 (3) (2011), pp. 434-438

Nederkoorn et al., 2016. C. Nederkoorn, L. Vancleef, A. Wilkenhöner, L. Claes, R.C. Havermans. Selfinflicted pain out of boredom. Psychiatr. Res., 237 (2016), pp. 127-132

F. Neziroglu, M. Mancebo. Skin picking as a form of self-injurious behavior. Psychiatr. Ann., 31 (9) (2001), pp. 549-555

Nock and Favazza, 2009. M.K. Nock, A.R. Favazza. Nonsuicidal self-injury: definition and classification. M.K. Nock (Ed.), Understanding Nonsuicidal Self-Injury: Origins, Assessment, and Treatment, American Psychological Association, Washington, DC, US (2009), pp. 9-18

Nock and Prinstein, 2004. M.K. Nock, M.J. Prinstein. A functional approach to the assessment of selfmutilative behavior. J. Consult. Clin. Psychol., 72 (5) (2004), p. 885

Oldershaw et al., 2008. A. Oldershaw, E. Grima, F. Jollant, C. Richards, M. Simic, L. Taylor, U. Schmidt. Decision making and problem solving in adolescents who deliberately self-harm. Psychol. Med., 39 (2008), p. 95

Pacan et al., 2014. P. Pacan, M. Grzesiak, A. Reich, M. Kantorska-Janiec, J.C. Szepietowski.

Onychophagia and onychotillomania: prevalence, clinical picture and comorbidities. Acta Derm. Venereol., 94 (1) (2014), pp. 67-71

Penzel, 2003. F. Penzel. The Hair-Pulling Problem: a Complete Guide to Trichotillomania. Oxford University Press, New York (2003)

Peterson et al., 2008. J. Peterson, S. Freedenthal, C. Sheldon, R. Anderson. Nonsuicidal self injury in adolescents. Psychiatry, 5 (2008), pp. 20-26

Roberts et al., 2013. S. Roberts, K. O'Connor, C. Bélanger. Emotion regulation and other psychological models for body-focused repetitive behaviors. Clin. Psychol. Rev., 33 (6) (2013), pp. 745-762

Robinson and Wilson, 2019. K. Robinson, M.S. Wilson. Open to Interpretation? Inconsistent Reporting of Lifetime Non-suicidal Self-Injury across Two Common Assessments. (2019) (Unpublished manuscript) 
Sacks et al., 2008. M.B. Sacks, A.M. Flood, M.F. Dennis, M.A. Hertzberg, J.C. Beckham. Self-mutilative behaviors in male veterans with posttraumatic stress disorder. J. Psychiatr. Res., 42 (6) (2008), pp. 487-494

Shusterman et al., 2009. A. Shusterman, L. Feld, L. Baer, N. Keuthen. Affective regulation in trichotillomania: evidence from a large-scale internet survey. Behav. Res. Ther., 47 (8) (2009), pp. 637-644

Snorrason et al., 2010. I. Snorrason, J. Smari, R.P. Olafsson. Emotion regulation in pathological skin picking: findings from a non-treatment seeking sample. J. Behav. Ther. Exp. Psychiatr., 41 (3) (2010), pp. 238-245

Snorrason et al., 2013. I. Snorrason, D.J. Stein, D.W. Woods. Classification of excoriation (skin picking) disorder: current status and future directions. Acta Psychiatr. Scand., 128 (2013), pp. 406-407

Stanley and Cohen, 1999. M. Stanley, L.J. Cohen. Trichotillomania and Obsessive-Compulsive Disorder. Trichotillomania. American Psychiatric Press, Washington DC (1999), pp. 225-261

Summerfeldt et al., 2004. L.J. Summerfeldt, P.H. Kloosterman, M.M. Antony, M.A. Richter, R.P. Swinson. The relationship between miscellaneous symptoms and major symptom factors in obsessive-compulsive disorder. Behav. Res. Ther., 42 (12) (2004), pp. 1453-1467

Summerfeldt et al., 2014. L.J. Summerfeldt, P.H. Kloosterman, M.M. Antony, R.P. Swinson. Examining an obsessive-compulsive core dimensions model: structural validity of harm avoidance and incompleteness. J. Obsessive-Compulsive Relat. Disord., 3 (2014), pp. 83-94

Suyemoto, 1998. K.L. Suyemoto. The functions of self-mutilation. Clin. Psychol. Rev., 18 (5) (1998), pp. 531-554

Swannell et al., 2014. S.V. Swannell, G.E. Martin, A. Page, P. Hasking, N.J. St John. Prevalence of nonsuicidal self-injury in nonclinical samples: systematic review, meta-analysis and metaregression. Suicide Life-Threatening Behav., 44 (3) (2014), pp. 273-303

Taylor et al., 2014. S. Taylor, D. Mckay, K.B. Crowe, J.S. Abramowitz, C.A. Conelea, J.E. Calamari, C. Sica. The sense of incompleteness as a motivator of obsessive-compulsive symptoms: an empirical analysis of concepts and correlates. Behav. Ther., 45 (2) (2014), pp. 254-262

Teng et al., 2004. E.J. Teng, D.W. Woods, B.A. Marcks, M.P. Twohig. Body-focused repetitive behaviors: the proximal and distal effects of affective variables on behavioral expression. J. Psychopathol. Behav. Assess., 26 (1) (2004), pp. 55-64

Twohig and Woods, 2001. M.P. Twohig, D.W. Woods. Habit reversal as a treatment for chronic skin picking in typically developing adult male siblings. J. Appl. Behav. Anal., 34 (2) (2001), pp. 217220

Walther et al., 2009. M.R. Walther, C.A. Flessner, C.A. Conelea, D.W. Woods. The milwaukee inventory for the dimensions of adult skin picking (MIDAS): initial development and psychometric properties. J. Behav. Ther. Exp. Psychiatr., 40 (1) (2009), pp. 127-135

Wetterneck et al., 2006. C.T. Wetterneck, D.W. Woods, M.M. Norberg, A.M. Begotka. The social and economic impact of trichotillomania: results from two nonreferred samples. Behav. Interv.: Theor. Pract. Resid. Community-Based Clin. Prog., 21 (2) (2006), pp. 97-109

Wilhelm et al., 1999. S. Wilhelm, N.J. Keuthen, T. Deckersbach, I.M. Engelhard, A.E. Forker, L. Baer, et al. Self-injurious skin picking: clinical characteristics and comorbidity. J. Clin. Psychiatr., 60 (7) (1999), pp. 454-459

Wilkinson and Goodyer, 2011. P. Wilkinson, I. Goodyer. Non-suicidal self-injury. Eur. Child Adolesc. Psychiatr., 20 (2) (2011), pp. 103-108

Wilkinson et al., 2011. P. Wilkinson, R. Kelvin, C. Roberts, B. Dubicka, I. Goodyer. Clinical and psychosocial predictors of suicide attempts and nonsuicidal self-injury in the Adolescent 
Depression Antidepressants and Psychotherapy Trial (ADAPT). Am. J. Psychiatr., 168 (5) (2011), pp. 495-501

Zetterqvist et al., 2013. M. Zetterqvist, L.G. Lundh, Ö. Dahlström, C.G. Svedin. Prevalence and function of non-suicidal self-injury (NSSI) in a community sample of adolescents, using suggested DSM5 criteria for a potential NSSI disorder. J. Abnorm. Child Psychol., 41 (2013), pp. 759-773

${ }^{1}$ Both authors contributed equally to this manuscript.

${ }^{2}$ We conducted additional analyses including individuals with BFRBs who reported heightened symptom severity at a comparable level to that of the NSSI group ( $n=165$; severity $M=8.70$, $S D=2.55)$. The selected BFRB groups included individuals with hair pulling $(n=47$; severity $M=8.66, S D=2.00)$, skin picking $(n=92$; severity $M=8.67, S D=1.71)$, nail picking $(n=46$; severity $M=8.70, S D=1.44)$, nail biting $(n=126$; severity $M=8.67, S D=1.78)$, and cheek biting ( $n=61$; severity $M=8.67, S D=1.91$ ). The selected BFRB sample included 371 individuals (= approximately the top $28 \%$ of the original BFRB sample). Thus, all BFRB and NSSI groups had equivalent severity scores (=approximately 8.70). Using these samples, we repeated our main analyses on the 11 key clinical features across the three domains. The overall findings remained largely identical to those based on the entire study sample. We also repeated the same analyses by collapsing all the BFRB groups ( $n=371$, severity $M=8.67, S D=1.77$ ) in comparison to the NSSI group. The overall pattern of findings remained unchanged. In summary, compared to the BFRB groups, the NSSI group reported significantly lower automatic behaviors, lower trance-like behavior, and greater routine/ritualistic behavior ( $p s<.001)$. The NSSI group also reported significantly greater motivation to relieve feelings of emptiness or feel something, communicate or seek attention, and achieve a "just right" feeling, but lower motivation to alter appearance ( $p s<.001$ ). As a consequence of engaging in the behavior, the NSSI also reported a significantly greater reduction in tension or anxiety, greater gratification, but lower reduction in boredom ( $p s<.001$ ). These results suggest that the observed differences in clinical features between the NSSI and the BFRB groups are not merely due to the different levels of overall symptom severity. 